D.O.I.:10.3895/S1808-04482012000100008

\title{
DETERMINANTES DA DIFUSÃO DO MÉTODO DE CUSTEIO 'UNIDADE DE ESFORÇO DE PRODUÇÃO’' (UEP) NA INDÚSTRIA TÊXTIL CEARENSE
}

\section{THE DIFFUSION DETERMINANTS OF THE 'PRODUCTION EFFORT UNIT' (PEU) COSTING METHOD IN THE CEARÁ TEXTILE INDUSTRY}

\author{
Leonardo Almeida de Sousa ${ }^{1}$; Hugo Santana de Figueirêdo Junior ${ }^{2}$ \\ ${ }^{1}$ Universidade Federal do Ceará - UFC - Fortaleza - Ceará - Brasil \\ leonardo.almsousa@gmail.com \\ 2 Universidade Federal do Ceará - UFC - Fortaleza - Ceará - Brasil \\ hugo.figueiredo@ufc.br
}

\begin{abstract}
Resumo
O método Unidade de Esforço de Produção (UEP) fundamenta-se na noção de esforço de produção, isto é, de esforço dos fatores direta ou indiretamente aplicados na fabricação do produto, tratando entidades multiprodutoras como monoprodutoras, para determinar o custo unitário dos seus produtos. O objetivo deste artigo é identificar os determinantes da difusão do método de custeio UEP na indústria têxtil cearense. Trata-se de uma pesquisa qualitativa, com questionário semi-estruturado, junto a empresas têxteis localizadas no Estado do Ceará, seguida de outra pesquisa documental junto a instituições de ensino superior também do Estado, ambas complementadas por um estudo de caso de uma empresa local do ramo têxtil. A análise dos resultados permite constatar que há benefícios econômicos pela adoção do UEP em relação ao método de custeio por absorção tradicional mais utilizado. Porém, o legado investido em capital físico e intelectual no uso de outros métodos de custeio no parque têxtil cearense, assim como a dificuldade de observação dos benefícios do UEP, tanto na academia quanto em outras empresas, revelam-se como principais causas da não adoção do UEP no parque têxtil cearense até o momento.
\end{abstract}

Palavras-chave: unidade de esforço de produção; métodos de custeio; indústria têxtil.

\section{Introdução}

No ambiente atual de negócios, onde os consumidores têm diversas opções de escolha entre mercadorias similares, as empresas têm que apresentar produtos a preços competitivos e com qualidade suficiente para corresponder às necessidades dos compradores. Assim, cada vez mais se faz necessária uma adequada gestão dos custos, de modo a maximizar os resultados do portfólio de produtos fabricados e comercializados.

\footnotetext{
* Uma versão preliminar deste artigo foi publicada nos anais do $4^{\circ}$ Congresso UFSC de Controladoria e Finanças, realizado em Florianópolis/SC, entre 18 e 20 de abril de 2011. A presente versão contempla também as sugestões dos revisores ad hoc e dos congressistas desse evento, a quem os autores são gratos.
} 
As empresas dispõem de vários métodos para determinar os custos unitários de seus produtos, para fins de decisão. Dentre esses, o método de custeio UEP pode ser considerado inovador, mais moderno, em relação aos métodos de custeio tradicionais por absorção (AGUIRRE, 1998).

Esse método teve sua origem na Europa e seu uso não é recente no Brasil, sendo utilizado principalmente por empresas industriais sediadas no Sul do país, como Sadia/Perdigão, Seara, Tramontina e Boticário (SAKAMOTO, 2003). Entretanto, no Ceará, o UEP não é difundido, embora, a princípio, haja potencial para sua utilização devido ao diversificado parque industrial do Estado. Nesse contexto, é importante a identificação de determinantes da difusão dessa inovação gerencial, para compreender a competitividade das empresas e das indústrias.

Segundo Diamond (2005), há quatro fatores que influenciam a difusão das inovações em uma mesma sociedade: a vantagem econômica relativa da inovação; o valor social ou prestígio da tecnologia existente, que pode se sobrepor ao benefício econômico; a compatibilidade da inovação com o capital já investido; e, a facilidade com que as vantagens da inovação podem ser observadas.

Então, este trabalho busca responder a seguinte questão problema: quais motivos levam à utilização ou não do método UEP no parque têxtil cearense? Assim, seu objetivo principal é identificar os determinantes da difusão do método de custeio UEP nas empresas têxteis do Estado do Ceará. A escolha do setor têxtil se deu pela sua importância na economia do Brasil e do Ceará: o país é o sexto maior produtor mundial e o Ceará é um de seus pólos mais importantes, posicionando-se, em 2007, como o quinto maior estado exportador (ABIT, 2010).

Assim, neste artigo, relatam-se duas pesquisas de campo e um estudo de caso. Inicialmente, é realizada uma breve revisão da literatura acerca dos principais métodos de custeio, mantendo-se o foco no custeio UEP. Em seguida, apresentam-se os resultados das pesquisas realizadas em empresas têxteis e em instituições de ensino superior do estado do Ceará, visando observar a presença do método nos meios profissional e educacional. Posteriormente, caracteriza-se a empresa onde foi realizado o estudo de caso, menciona-se como foi efetuada a coleta de dados, e descrevemse as etapas para determinação do custo de fabricação dos produtos pela utilização do método UEP, em comparação com o método de absorção tradicional atualmente utilizado. Por último, são elencadas as conclusões oriundas do estudo.

Em termos teóricos, esse estudo poderá ser útil como referência a outros trabalhos que abordem a difusão de métodos de custeio, mostrando como está a gestão de custos nas maiores empresas têxteis e como o sistema de educação trata o tema de métodos de custeio no estado do Ceará. E em termos práticos, além de subsidiar os empresários e suas equipes com conhecimentos gerais sobre os modelos de gestão de custos aplicados às grandes indústrias têxteis do estado do Ceará, o trabalho possibilitará contribuir para a divulgação e, até mesmo, para a adoção do método 
UEP em outros segmentos industriais.

\section{Referencial teórico}

\subsection{Métodos de custeio}

Diversos são os métodos de custeio que podem ser utilizados pelas empresas, para se determinar o custo de produtos/serviços (LEONE, 2000). Cada método de custeio tem características próprias, podendo em uma mesma situação apresentar resultados diferentes. Cabe ao responsável pelos custos da entidade optar pelo método de custeio que melhor se adapte à estrutura física e operacional da sua empresa. Além disso, deve considerar aquele que mais pode contribuir na análise dos custos e dar suporte na busca de vantagens competitivas para a empresa. No entanto, como bem observa Martins (2008), nenhum método possui capacidade de solucionar todos os problemas, isso porque precisa desenvolver-se e aprimorar-se para conseguir atingir sua capacidade de funcionar como instrumento de administração.

Dentre os métodos de custeios abordados na literatura nacional, destacam-se: o custeio por absorção, o custeio direto/variável, o custeio pleno ou integral (RKW), o custeio baseado em atividades $(\mathrm{ABC})$ e sua variação mais recente - o ABC direcionado pelo tempo (TDABC), e o UEP.

\subsubsection{Custeio por absorção}

No custeio por absorção, os produtos fabricados absorvem todos os custos ocorridos no período, tendo eles participação direta ou indireta na fabricação. São apropriados aos produtos ou serviços todos os custos de produção, e só os de produção (MARTINS, 2008).

Para Padoveze (2006), esse método é consistente com o modelo oficial de apuração dos resultados das empresas, tendo as seguintes características:

- Utiliza os custos diretos industriais;

- Utiliza os custos indiretos industriais, por meio de critérios de rateio;

- Não utiliza os gastos administrativos;

- Não utiliza gastos comerciais.

Ainda, de acordo com Martins (2008), esse método, com suas variações, é utilizado amplamente para atender a legislação do imposto de renda no Brasil e por obedecer aos princípios de competência e confrontação dos gastos com as receitas do período. Na sua forma mais comum, o custeio por absorção utiliza um ou mais direcionadores baseados em volume de produção para atribuir custos indiretos aos produtos.

\subsubsection{Custeio direto/variável}

Diferentemente do custeio por absorção, esse método não incorpora custos indiretos de 
fabricação no custo do produto, somente os diretos. Ou de outra forma, apenas gastos que irão variar com a quantidade produzida são considerados no custo do produto. Na verdade, como a maior parte dos custos variáveis é direta, e vice-versa, os métodos direto e variável costumam ser tratados como um só.

No custeio variável, apenas os custos variáveis são alocados aos produtos, os fixos são considerados como despesas do período e vão diretamente para o resultado, enquanto para os estoques só seguem naturalmente os custos variáveis (FERREIRA, 2007).

\subsubsection{Custeio pleno ou integral (RKW)}

O Reichskuratorium für Wirtschaftlichkeit (RKW), de origem alemã, busca a apropriação aos produtos de todos os custos e despesas ocorridos em determinado período da produção, fazendo parte do custo unitário do produto as parcelas de custo direto e indireto, além das despesas administrativa, comercial e financeira que lhe corresponde, utilizando-se de critérios de rateio para determinação desses valores (MARTINS, 2008).

Esse método utiliza o conceito de absorção tanto para os custos como para todas as despesas, então pode ser visto como um caso particular do custeio por absorção.

\subsubsection{Custeio baseado em atividades (ABC)}

O custeio ABC (do inglês Activity Based Costing) consiste em identificar as atividades de cada departamento, bem como calcular os custos de cada atividade mediante identificação dos direcionadores de custos, de modo que os produtos e serviços recebem parte dessas atividades, mediante efetiva utilização dos recursos (NAKAGAWA, 1994). Dessa forma, não são adotados os tradicionais critérios de rateio baseados em volume, na maioria das vezes, arbitrários e sem relação efetiva com os causadores de custos.

De acordo com Brimson (1996), o método ABC está baseado no princípio de que as atividades consomem recursos, enquanto produtos, clientes ou outros objetivos de custo consomem atividades. O custeio é realizado pelo rastreamento dos custos indiretos de fabricação de um produto ou serviço, através da identificação direta com as atividades relacionáveis e pela determinação de quanto de cada atividade é dedicado ao objetivo de custo. Ou seja, o ABC também é um método de custeio por absorção.

Na sua variação recente, o Time-driven $\mathrm{ABC}$ (TDABC), permanece o princípio básico de relacionar os custos indiretos às suas causas, desta feita com direcionadores baseados no tempo (KAPLAN; ANDERSON, 2004).

\subsection{Método de unidade de esforço de produção (UEP)}

\subsubsection{Origens do método}


O método de Unidade de Esforço de Produção nasceu na França, à época da Segunda Guerra Mundial, através do engenheiro Georges Perrin. De acordo com Allora e Allora (1995), Perrin considerava que se o método alemão RKW criava e utilizava uma unidade de medida abstrata para medir a produção diversificada em uma seção homogênea, portanto, deveria haver um meio de criar uma unidade de medida para medir a produção diversificada, não em uma única seção, mas na fábrica inteira. Dos estudos que realizou, Perrin desenvolveu sua própria unidade de medida da produção, a qual denominou com suas iniciais “GP”.

$\mathrm{Na}$ França, o método caiu em esquecimento após o falecimento de Perrin. Segundo Bornia (2002), Franz Allora, um discípulo de Perrin, modificou o método GP, criando o que denominou método de Unidades de Produção (UPs), ou método das UEPs, e o trouxe para o Brasil no início da década de 1960. Em 1978, passou-se a implantar este método de custeio em empresas do interior de Santa Catarina, quando foi criada uma empresa de consultoria em Blumenau, especializada na implantação desse método, chegando a colocá-lo em uso em cerca de 30 empresas daquele Estado. Conforme Wernke (2004), o método UEP vem sendo utilizado no Brasil por mais de uma centena de empresas, principalmente nos Estados do Paraná, Santa Catarina e Rio Grande do Sul.

Um método de custeio que apresenta algumas similaridades ao UEP é o método alemão Äquivalenzziffern (Cifras de Equivalência). Dentro de uma perspectiva histórica, pode-se supor que o método UEP é uma evolução do método das Cifras de Equivalência, o qual se desenvolveu no início do século XX. No entanto, não há evidências de que ambos possuam raízes comuns (WALTER et al., 2005).

Já na literatura internacional de custos mais difundida no Brasil, produzida por autores americanos como Blocher et al. (2007) e Atkinson et al (2008), não costuma haver referência ao método UEP.

\subsubsection{Conceitos e características do método UEP}

De acordo com Allora e Allora (1995), não existem informações ou decisões a tomar que não devam estar diretamente relacionadas ao conceito de produção. Quando as empresas possuem vários procedimentos sendo executados ao longo da linha de produção, tendo processo fabril complexo e uma produção diversificada, torna-se mais complicada a gestão das atividades no ambiente fabril, principalmente no que se refere à alocação de custos indiretos aos itens fabricados. Para tais situações, há a necessidade de empregar metodologias de custeamento mais aprimoradas, como é o caso do método das Unidades de Esforço de Produção (UEP).

Segundo Bornia (2002), pelo método do UEP há uma simplificação da forma de cálculo da produção do período, mediante a utilização de uma unidade de medida comum a todos os produtos (e processos) da empresa. 
O método baseia-se na unificação da produção, na qual é realizada por meio de uma unidade de medida comum aos produtos e processos da empresa, a própria UEP, que possibilita a realização de atividades de planejamento, controle e analise de desempenho da produção (FERREIRA, 2007). Dessa forma, os esforços realizados para a fabricação passam a ser medidos por uma unidade comum a todos os produtos.

No método UEP, para Bornia (2002), os custos unitários dos produtos são resumidos em custos das matérias-primas consumidas e em custos de transformação. Quanto às matérias primas consumidas, o custeio de cada produto é obtido facilmente. Logo, o método se preocupa basicamente com os custos de transformação, diretos e indiretos. Estes são conhecidos também como custos de conversão ou custos de agregação e representam o esforço agregado pela empresa na obtenção do produto. São todos os custos de produção, exceto matérias-primas, os componentes adquiridos prontos e as embalagens compradas.

Então, na verdade, o método é mais um caso particular do custeio por absorção, em que custos indiretos são atribuídos a produtos segundo determinadas regras.

\subsubsection{Vantagens e desvantagens do método UEP}

No que tange às vantagens obtidas com a implantação do método UEP, Allora e Allora (1995) defendem que a vantagem principal reside na homogeneidade que esse método propicia. Ou seja, quaisquer que sejam os objetos fabricados e seus processos de fabricação, a produção dos mesmos precisa de uma parte desse elemento único que é o esforço de produção desenvolvido pela usina. E Bornia (2002) complementa que a grande vantagem do método da UEP é sua simplicidade de operacionalização.

Como limitação, há o fato de que o UEP volta-se apenas para a determinação do custo de transformar matérias-primas em produtos prontos, não permitindo a gestão dos gastos administrativos (WERNKE, 2005). Assim, também haveria dificuldades em utilizá-lo em empresas prestadoras de serviços, cuja parcela relevante dos gastos não é de transformação.

Bornia (2002) acrescenta como desvantagem a dificuldade no tratamento dos desperdícios, pois o método não fornece a parcela de custos devida a desperdícios, já que as atividades auxiliares não são detalhadas, seus custos são jogados para os postos operativos e se perde a noção dos desperdícios nesse processo.

Além do mais, empresas industriais com produção sob encomenda e cujos produtos não são repetitivos não conseguem estabelecer uma unidade de medida de produção comum e ficam impossibilitadas de utilizar o UEP.

\subsubsection{Aplicação do método UEP}


A produção de uma fábrica, durante um determinado período, corresponde ao conjunto de produtos fabricados, estejam eles acabados ou em elaboração. Quando há apenas a fabricação de um produto, os cálculos de custos e o controle de desempenho são bastante simplificados, devido ao processo produtivo ser também, simplificado, bastando dividir o custo total do período pelo número de unidades produtivas, tendo-se, assim, o custo unitário.

Bornia (2002) comenta que a unificação da produção no método da UEP parte do conceito teórico de esforço de produção e que os esforços de produção representam todo esforço despendido no sentido de transformar a matéria-prima nos produtos acabados da empresa. Assim, os esforços de produção são os gastos ocorridos durante o processo produtivo da empresa e que foram consumidos pelos produtos elaborados em determinado período, portanto a esses devem ser atribuídos.

Ferreira (2007, p.274) afirma que o objetivo do método é "transformar uma produtora de vários bens em uma empresa monoprodutora e, assim, simplificar o controle físico e o controle financeiro". Em empresas multiprodutoras tem-se uma maior dificuldade de alocação de custos, a fim de se amenizar esse problema, procede-se com a unificação da medida da produção, a qual se fundamenta na noção de esforço de produção.

Segundo Wernke (2004) e Fraga et al. (2010), a implantação do método da UEP pode ser dividida em cinco etapas básicas e seqüenciais, detalhadas a seguir:

a) Divisão da fábrica em postos operativos: os postos operativos representam as operações de transformação homogêneas ou semelhantes que são realizadas pela empresa no processo produtivo e são constituídos por uma ou mais operações produtivas elementares. Definidos os postos operativos, a segunda ação é calcular os índices de custos de cada posto operativo;

b) Cálculo dos índices de custos (ou foto-índices): os índices de custos são representados pelos custos por hora de funcionamento de cada posto operativo, ou seja, pelo valor gasto pela empresa para manter determinada operação funcionando por uma hora de trabalho. Para calculá-lo, basta dividir o total dos custos de transformação do posto operativo em determinado período pelo número previsto de horas de trabalho no mesmo período;

c) Escolha do produto-base: para auxiliar o processo de análise dos custos incorridos nos postos operativos e, conseqüentemente, na empresa, adota-se um produto-base que represente o custo de produção de uma unidade de produto. Esse custo de produção representará o valor de uma unidade de UEP. O produto-base pode ser um produto realmente existente, uma combinação de produtos, um produto fictício ou ainda, uma média dos tempos de passagem dos produtos pelos postos operativos. Assim, a escolha do produto base deve recair preferencialmente sobre aquele que ocupar o maior número de postos operativos em seu processo produtivo. Então, o custo do produtobase (ou o custo de uma UEP) será obtido pela soma dos resultados obtidos através da 
multiplicação do tempo de passagem do produto-base em cada posto operativo pelo respectivo índice de custo desse posto operativo;

d) Cálculo dos potenciais produtivos: o potencial produtivo representa quantas unidades do produto-base poderiam ser produzidas em uma hora de operação do posto operativo. Tal capacidade é medida pela divisão do índice de custo (obtido no segundo passo da implantação) pelo custo do produto-base (obtido no terceiro passo da implantação);

e) Determinação dos equivalentes dos produtos: essa etapa do processo consiste em determinar os equivalentes dos produtos em termos de UEP. Para obtê-los, multiplica-se o potencial produtivo do posto pelo tempo de passagem do produto nesse posto e soma-se o total para cada produto. O somatório das UEPs consumidas pelo produto em todos os postos operativos em que passar determinará a quantidade total de UEPs para cada produto.

\section{Metodologia}

No que se refere aos aspectos metodológicos, este artigo está alicerçado em uma revisão da literatura, seguida por uma pesquisa de campo, outra documental e um estudo de caso. Uma pesquisa está voltada para a área profissional, encaminhada aos responsáveis pela contabilidade de custos das empresas. A outra aborda a área educacional acadêmica do curso de Ciências Contábeis. Finaliza-se o trabalho com um estudo de caso em uma empresa têxtil. O objetivo geral é identificar os determinantes da difusão do método UEP no parque têxtil cearense.

A fundamentação teórica do trabalho ocorreu através de pesquisa documental e bibliográfica, conforme definida por Santos (2007). Efetuou-se a análise das informações obtidas e abordou-se a teoria dos métodos de custeio, com ênfase para o método UEP.

A pesquisa de campo, qualitativa, com questionário semi-estruturado, consistiu em verificar o método de custeio mais utilizado nas empresas do ramo têxtil do estado do Ceará e descobrir os motivos pelos quais o método de custeio UEP era ou não adotado. Foi enviado questionário às empresas selecionadas, direcionado ao profissional responsável pela área de custos.

O universo dessa pesquisa é constituído pelas empresas têxteis situadas no Estado do Ceará: de um total de 440 empresas industriais têxteis no Ceará, apenas 18 são de portes médio ou grande, com mais de 100 funcionários (IBGE, 2008). Seguindo a recomendação de Gil (2002) para delimitação de pesquisas, selecionou-se uma amostra de oito empresas têxteis com base no ranking das maiores empresas do Ceará (O POVO, 2009). Essa amostra tende a ser bem representativa de empresas com maior capacidade de gestão no Estado, pois são as maiores empresas que normalmente têm acesso às inovações gerenciais.

Por se tratar de um questionário relativamente simples, com questões objetivas, as informações foram coletadas através de contato direto (visitas às entidades) e por meios de 
comunicação (telefone, emails), o que possibilitou um estudo dinâmico, sem o uso de elementos estatísticos para a análise dos resultados.

Já a pesquisa documental visou observar qual tratamento acadêmico está sendo dado, na formação de pessoal, para o método UEP nas disciplinas relacionadas à Contabilidade de Custos. O universo dessa pesquisa é constituído por 34 Instituições de Ensino Superior (IES) que ofertam curso superior de Ciências Contábeis no Ceará (INEP, 2009), sendo selecionadas nove entre as que possuem maior número de alunos matriculados. A coleta de dados foi realizada através de contato com alunos, professores ou com a própria entidade, solicitando-se a ementa das disciplinas de Análise de Custos/Contabilidade de Custos.

Por fim, relacionado ao estudo de caso, optou-se pela análise das particularidades de uma unidade fabril têxtil, desenvolvendo um processo de implantação adequado ao setor. O protocolo para este estudo de caso teve como ponto de partida as pesquisas bibliográficas e a compreensão dos métodos de custeio mais utilizados na indústria têxtil, com especial atenção ao UEP. A principal questão do estudo de caso referiu-se à identificação prática de eventuais benefícios econômicos resultantes da implantação do UEP em empresas têxteis, representada por uma empresa industrial têxtil cearense de grande porte (anônima neste artigo), objeto do estudo de caso e onde foram realizadas as coletas dos dados durante um trimestre, mais especificamente nos processos de malharia e beneficiamento dos produtos.

\section{Resultados}

\subsection{Pesquisa junto às empresas do ramo têxtil}

O questionário da pesquisa de campo foi aplicado às oito maiores empresas têxteis do Ceará, todas na Região Metropolitana de Fortaleza. Foram levantados os seguintes pontos: a ferramenta utilizada para apuração de custos, o método/critério de rateio utilizado para distribuição dos custos aos produtos, o conhecimento sobre o método UEP e o porquê de não utilizá-lo, quando fosse o caso.

Quanto à ferramenta que a empresa utiliza para apuração dos custos, percebe-se a grande presença de planilhas eletrônicas (Tabela 1). Os sistemas integrados estão se desenvolvendo, mas ainda existe uma grande dificuldade de adaptação do sistema à estrutura fabril de determinadas empresas.

Tabela 1 - Ferramenta utilizada para apuração de custos

\begin{tabular}{lc}
\hline \multicolumn{1}{c}{ Ferramentas } & Quantidade \\
\hline Sistema Integrado & 3 \\
Planilhas & 5 \\
Não temos apuração & - \\
Outros & - \\
\hline \multicolumn{2}{c}{ Fonte: Pesquisa de campo (2010) }
\end{tabular}


Quanto ao método/critério de rateio que a empresa utiliza para distribuição dos custos indiretos aos produtos fabricados, as empresas pesquisadas usam o regime de apuração baseado na absorção tradicional dos custos, aplicando-se rateios com um ou mais direcionadores, entre eles: horas produzidas, $\mathrm{n}^{\circ}$ de batidas na tecelagem, tempos de tingimento e quantidades produzidas. Apenas uma empresa utiliza o ABC e nenhuma utiliza o UEP (Tabela 2). Um dos motivos da não utilização do UEP poderia ser o não conhecimento do método, porém observa-se que todos os profissionais de custos questionados declararam que conhecem o método, mas não o utilizam (Tabela 3).

Tabela 2 - Método/Critério utilizado para rateio dos custos

\begin{tabular}{|c|c|}
\hline Método/Critério de rateio utilizado & Quantidade \\
\hline Único Direcionador & 3 \\
\hline Vários Direcionadores & 4 \\
\hline ABC (Custeio Baseado em Atividades) & 1 \\
\hline UEP (Unidade de Esforço de Produção) & - \\
\hline Outros & - \\
\hline \multicolumn{2}{|c|}{ Fonte: Pesquisa de campo (2010) } \\
\hline \multicolumn{2}{|c|}{ Tabela 3 - Conhecimento sobre UEP } \\
\hline Conhece o UEP? & Quantidade \\
\hline Sim, conheço e o utilizo & - \\
\hline Sim, conheço, mas utilizo outro & 8 \\
\hline Não & - \\
\hline
\end{tabular}

Embora a ausência de pessoal preparado para usar o UEP e a impossibilidade de usar o sistema de informação de custos existente com o UEP apareçam como barreiras ao uso do método, na verdade, a maioria das empresas simplesmente listou como motivo da não adoção do UEP o fato de não ser este o método de sua preferência, sem inicialmente especificar o porquê (Tabela 4). Um questionamento posterior revelou que os gestores não foram devidamente expostos aos benefícios do uso do método, seja na academia, durante a sua formação, ou através de consultorias e experimentos em casos práticos. E, por isso, temem os riscos de mudar o legado em sistemas e pessoal.

Tabela 4 - Motivo da não utilização do método

\begin{tabular}{lc}
\hline \multicolumn{1}{c}{ Por que não utiliza o Método UEP? } & Quantidade \\
\hline O sistema não está preparado ou não fornece está opção & 1 \\
Não temos pessoal preparado & 1 \\
Por opção da empresa & 6 \\
É um método muito complexo & - \\
Outros & - \\
\hline
\end{tabular}

Fonte: Pesquisa de campo (2010)

\subsection{Pesquisa junto às Instituições de Ensino Superior}

Com os resultados da pesquisa de campo, levantou-se a necessidade de se identificar como as IES do estado do Ceará, que ofertam o curso de graduação em Ciências Contábeis, estariam 
abordando o método em estudo na sua grade curricular. Afinal, os estudantes, que se tornarão profissionais da área contábil, necessitam ter conhecimento do método para difundirem o mesmo. Sendo assim, coletou-se, através de alunos, professores, departamentos e coordenações de curso, a ementa das disciplinas de Análise de Custos e de Contabilidade de Custos, na qual se apresentam os métodos e critérios de custeio desenvolvidos na contabilidade de custos.

Do universo de 34 IES que ofertam o curso de Ciências Contábeis no Ceará, a amostra dessa pesquisa de campo foi de nove, incluindo as grandes IES públicas e privadas, com maior número de profissionais no mercado: Universidade Federal do Ceará (UFC), Universidade Estadual do Ceará (UECE), Universidade de Fortaleza (UNIFOR), Faculdade Integrada do Ceará (FIC), Faculdade 7 de Setembro (FA7), Faculdades Nordeste (FANOR), Universidade Cearense (UNICE), Faculdade Integrada da Grande Fortaleza (FGF) e Faculdades Cearenses (FAC).

Dentre as instituições pesquisadas, nenhuma delas continha em sua ementa, como um item ou um subitem, a descrição explícita da abordagem sobre o método de Unidade de Esforço de Produção. Percebeu-se que o método não tem o destaque necessário dentro das disciplinas de Análise de Custos e Contabilidade de Custos. Observou-se que nas ementas são abordados os tópicos "Métodos de Custeio" ou "Sistemas de Custeios" de um modo geral, o que não impede que o método de UEP seja comentado dentro deste tópico de uma maneira breve. Em outros casos, as ementas descrevem os métodos de custeamento e os resumem em absorção, variável, ABC e outros, podendo o método em estudo até ser debatido dentro do grupo de outros, mas também sem maior foco.

\subsection{Estudo de caso}

Esse estudo foi realizado junto a uma empresa industrial têxtil de grande porte no Ceará, produtora de fios e malhas, aqui anônima por motivo de confidencialidade das suas informações. Para o estudo em questão, foi utilizada apenas a sua unidade fabril de malhas.

A empresa produz cerca de 300 toneladas de malhas por mês. A principal matéria prima é o fio, de algodão, poliéster ou fibra sintética. A partir do fio, o processo fabril produz a malha, inicialmente chamada de malha crua, que segue para os processos de tingimento e beneficiamento, tornando-se o produto final comercializado. Seus principais produtos são meias-malha, cottons, viscoses e moletons de cores diversas.

Em relação à estrutura do processo produtivo da fábrica, a primeira etapa é composta pela malharia, também conhecida como tecelagem, onde o fio é transformado em malha. Em seguida, a malha passa por um processo de tingimento onde é definida a cor do produto. Após a tinturaria, a malha segue por várias etapas de beneficiamento, onde são definidas sua largura, gramatura e forma, dentre outras características específicas do produto, até chegar à embalagem (Figura 1). 
Figura 1 - Fluxo do processo produtivo de malhas

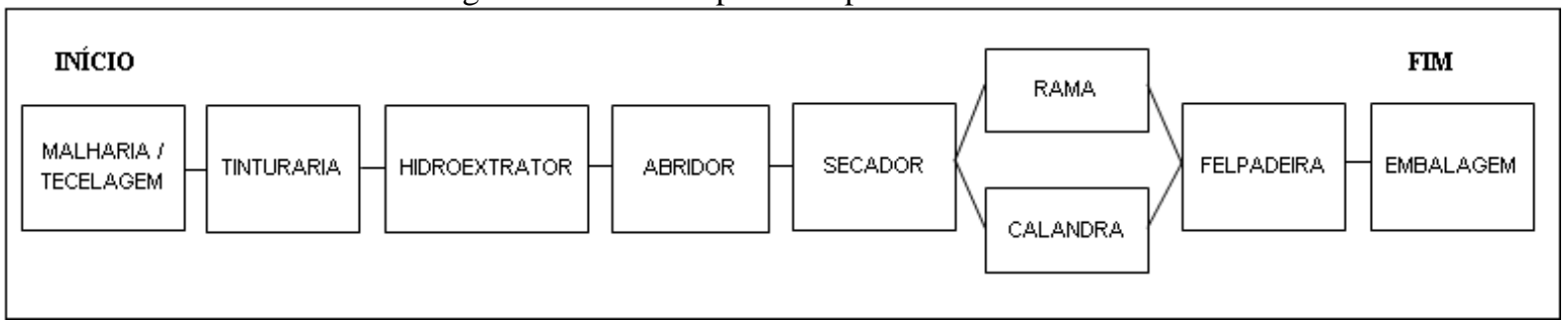

Fonte: Elaborado pelos autores com dados da empresa (2010)

Cada etapa descriminada no fluxo é composta por uma ou mais máquinas que realizam a mesma função: como exemplo tem-se os teares que são vários e possuem o mesmo papel de tecer a malha, integrando o processo de tecelagem ou malharia. A partir do fluxo apresentado, dividiu-se a fábrica em nove postos operativos (Quadro 1).

\begin{tabular}{|} 
Quadro 1- Postos operativos da unidade fabril \\
\hline Código & Posto Operativo \\
\hline P.01 & Malharia/Tecelagem \\
\hline P.02 & Tinturaria \\
\hline P.03 & Hidroextrator \\
\hline P.04 & Abridor \\
\hline P.05 & Secador \\
\hline P.06 & Calandra \\
\hline P.07 & Rama \\
\hline P.08 & Felpadeira \\
\hline P.09 & Revisão/Embalagem \\
\hline
\end{tabular}

Fonte: Elaborado pelos autores com dados da empresa (2010)

Os custos de transformação referentes a cada posto operativo foram extraídos da própria estrutura de centros de custos da empresa, que se assemelha à divisão de postos operativos proposta. Utilizou-se a média dos custos dos últimos três meses do ano de 2009. Percebe-se que o item de custo de transformação mais relevante é o de salários/encargos. Além disso, uma parcela considerável desses custos é incorrida no primeiro posto operativo. Admitindo-se que o número de horas a trabalhar mensalmente seja de 176 horas por pessoa, divide-se o custo total por posto operativo pelo número de horas trabalhadas para se obter o custo por hora de cada posto (Tabela 5).

Cada malha tem um percurso diferente dentro do processo e tempos diferentes de passagens nas máquinas. Como no processo de tingimento, o tempo de fabricação varia de acordo com a cor escolhida e o tipo de produto a ser fabricado, para facilitar o entendimento, foi utilizada uma cor média padrão para os produtos e, assim, tem-se um tempo médio de tingimento de cada produto. $\mathrm{Na}$ Tabela 6 são apresentados os tempos de passagens dos produtos, em minutos, por quilo, em cada posto. Onde não há o valor do tempo, o produto não passa por aquele posto. Os produtos possuem tempos de passagens totais similares, variando conforme os postos operativos. 
Tabela 5 - Custos mensais dos postos operativos $(\mathrm{R} \$)^{*}$

\begin{tabular}{|c|c|c|c|c|c|c|c|c|c|c|}
\hline \multirow{2}{*}{$\begin{array}{l}\text { Item de } \\
\text { custo }\end{array}$} & \multicolumn{10}{|c|}{ Posto operativo } \\
\hline & P.01 & P.02 & P.03 & P.04 & P.05 & P.06 & P.07 & P.08 & P.09 & $\begin{array}{c}\text { Total } \\
\text { (R\$) }\end{array}$ \\
\hline $\begin{array}{l}\text { Salários e } \\
\text { encargos }\end{array}$ & 136.549 & 73.630 & 54.970 & 4.301 & 26.298 & 10.894 & 30.495 & 8.203 & 28.142 & 373.483 \\
\hline $\begin{array}{l}\text { Energia } \\
\text { elétrica }\end{array}$ & 3.251 & 3.812 & 1.081 & 55 & 13.059 & 779 & 6.374 & 588 & 408 & 29.408 \\
\hline Manutenção & 89.265 & 18.178 & 24.017 & 1.429 & 4.828 & 3.528 & 45.703 & 1.231 & 626 & 188.805 \\
\hline Depreciação & 39.401 & 32.463 & 23.711 & 1.864 & 53.404 & 7.125 & 22.413 & 3.053 & 8.603 & 192.038 \\
\hline Outros & 6.765 & 53.483 & 2.838 & - & 1.619 & 568 & 1.266 & - & 25 & 66.564 \\
\hline Total & 275.232 & 181.567 & 106.617 & 7.650 & 99.208 & 22.894 & 106.252 & 13.074 & 37.804 & 850.299 \\
\hline $\begin{array}{l}\mathrm{N}^{o} \text { horas } \\
/ \mathrm{mês}\end{array}$ & 176 & 176 & 176 & 176 & 176 & 176 & 176 & 176 & 176 & - \\
\hline $\begin{array}{l}\text { Custo/hora } \\
\text { por mês }\end{array}$ & 1.564 & 1.032 & 606 & 43 & 564 & 130 & 604 & 74 & 215 & - \\
\hline
\end{tabular}

Fonte: Elaborado pelos autores com dados da empresa (2010)

* Média mensal do $4^{\circ}$ trimestre de 2009

Tabela 6 - Tempo de passagem de um quilo dos produtos pelos postos operativos (min.)

\begin{tabular}{lrrrrrrrrrr}
\hline \multirow{1}{*}{ Produto } & \multicolumn{10}{c}{ Posto operativo } \\
\cline { 2 - 11 } & P.01 & P.02 & P.03 & P.04 & P.05 & P.06 & P.07 & P.08 & P.09 & Total (min.) \\
\hline Meia-malha & 3,03 & 5,87 & 0,16 & - & 0,32 & 0,12 & - & - & 0,15 & 9,64 \\
Cotton & 3,11 & 6,25 & 0,18 & 0,15 & - & - & 0,39 & - & 0,26 & 10,34 \\
Viscose & 2,99 & 6,19 & - & 0,15 & 0,33 & - & 0,35 & - & 0,25 & 10,26 \\
Moleton & 2,87 & 6,14 & 0,10 & 0,80 & 0,28 & - & 0,23 & 0,27 & 0,24 & 10,92 \\
Total & 11,99 & 24,44 & 0,44 & 1,10 & 0,93 & 0,12 & 0,97 & 0,27 & 0,90 & 41,15 \\
\hline
\end{tabular}

Fonte: Elaborado pelos autores com dados da empresa (2010)

Observa-se que o produto que passa no P.06 (Calandra) não passa no P.07 (Rama). Trata-se da meia-malha, que é do tipo tubular, cujo processo é distinto das demais, malhas do tipo aberta. As malhas abertas todas passam pelo P.04 (Abridor), pois na Tecelagem a malha é feita tubular e nessa etapa ela passa a ser aberta. O moleton é o único produto que tem em seu percurso o P.08 (Felpadeira).

Para escolha do produto-base, optou-se por utilizar uma combinação entre dois produtos: meia-malha e moleton. Calculou-se a média entre tempos nos postos em que os dois produtos passam e considerou-se o tempo existente nos postos que somente um dos dois produtos passa. Assim, tem-se um produto combinado com passagem em todos os postos operativos. Dessa forma, calcula-se o custo do produto-base, dividindo-se o valor do custo/hora de cada posto pelo tempo de passagem do produto-base (Tabela 7).

Tabela 7 - Custo do produto base em UEP

\begin{tabular}{ccccccccccc}
\hline $\begin{array}{c}\text { Posto } \\
\text { operativo }\end{array}$ & $\mathbf{P . 0 1}$ & $\mathbf{P . 0 2}$ & $\mathbf{P . 0 3}$ & $\mathbf{P . 0 4}$ & $\mathbf{P . 0 5}$ & $\mathbf{P . 0 6}$ & $\mathbf{P . 0 7}$ & $\mathbf{P . 0 8}$ & $\mathbf{P . 0 9}$ & Total \\
\hline $\begin{array}{c}\text { Custo hora } \\
\text { por posto }\end{array}$ & 1.564 & 1.032 & 606 & 43 & 564 & 130 & 604 & 74 & 215 & NA \\
$\begin{array}{c}\text { Tempo do } \\
\text { produto- } \\
\text { base (min.) }\end{array}$ & 2,95 & 6,00 & 0,13 & 0,80 & 0,30 & 0,12 & 0,23 & 0,27 & 0,20 & NA \\
$\begin{array}{c}\text { Custo (R\$) } \\
4.608,41\end{array}$ & $6.192,43$ & 77,57 & 34,77 & 169,11 & 15,61 & 135,83 & 19,82 & 41,89 & $11.295,43$ \\
\hline
\end{tabular}

Fonte: Elaborado pelos autores com dados da empresa (2010) 


\section{NA: Não aplicável}

A soma do custo do produto-base em cada posto é igual a $\mathrm{R} \$ 11.295,43$ no período. A partir desse valor, a etapa seguinte é calcular os potenciais produtivos de cada posto, dividindo-se o custo/hora pelo valor total de UEP (Tabela 8). Observa-se que, em alguns postos operativos, o potencial produtivo é muito baixo, chegando a ser próximo de zero com duas casas decimais. Esse valor é para a produção de um quilo, por isso tão baixo, mas posteriormente os valores serão multiplicados pela produção total. Isso ocorre porque se tratam de postos operativos que possuem um baixo custo, nos quais os produtos passam rapidamente.

Tabela 8 - Cálculo do potencial produtivo de cada posto operativo

\begin{tabular}{lrrrrrrrrr}
\hline \multirow{2}{*}{ Item } & \multicolumn{10}{c}{ Posto operativo } \\
\cline { 2 - 10 } & $\mathbf{P . 0 1}$ & $\mathbf{P . 0 2}$ & $\mathbf{P . 0 3}$ & $\mathbf{P . 0 4}$ & $\mathbf{P . 0 5}$ & $\mathbf{P . 0 6}$ & $\mathbf{P . 0 7}$ & $\mathbf{P . 0 8}$ & P.09 \\
\hline Custo & & & & & & & & & \\
hora/posto & $1.563,82$ & $1.031,63$ & 605,78 & 43,46 & 563,68 & 130,08 & 603,71 & 74,29 & 214,80 \\
UEP & 11.295 & 11.295 & 11.295 & 11.295 & 11.295 & 11.295 & 11.295 & 11.295 & 11.295 \\
Potencial & & & & & & & & & \\
produtivo & 0,14 & 0,09 & 0,05 & 0,00 & 0,05 & 0,01 & 0,05 & 0,01 & 0,02 \\
\hline
\end{tabular}

Fonte: Elaborado pelos autores com dados da empresa (2010)

Em seguida, calcula-se o valor em UEP de cada produto, multiplicando-se o potencial produtivo do posto pelo tempo de passagem do produto no respectivo posto e somando para se ter o custo total (Tabela 9). Obteve-se o custo unitário de cada produto, em UEP, adicionando-se os valores de cada posto operativo.

A produção média mensal da empresa X está em torno de 280 a 300 toneladas de malhas. A partir do comportamento do mix de produção dos últimos três meses de 2009, adotou-se uma quantidade produzida de 285 toneladas. Dessa forma, utilizando a produção em quilos do período e sabendo-se os custos unitários equivalentes em UEP das malhas, chega-se ao custo do esforço da produção total do período pela multiplicação dessas grandezas. O próximo passo é descobrir quanto custa uma UEP e, para isso, divide-se o custo total de produção pelo total de UEPs produzidas (Tabela 10).

Tabela 9 - Cálculo da equivalência dos produtos em UEP

\begin{tabular}{lrrrrrrrrrr}
\hline & \multicolumn{10}{c}{ Posto operativo } \\
\cline { 2 - 11 } & P.01 & P.02 & P.03 & P.04 & P.05 & P.06 & P.07 & P.08 & P.09 & Total \\
\hline Meia-malha & 0,42 & 0,54 & 0,01 & - & 0,02 & 0,00 & - & - & 0,00 & 0,98 \\
Cotton & 0,43 & 0,57 & 0,01 & 0,00 & - & - & 0,02 & - & 0,00 & 1,04 \\
Viscose & 0,41 & 0,56 & - & 0,00 & 0,02 & - & 0,02 & - & 0,00 & 1,02 \\
Moleton & 0,40 & 0,56 & 0,01 & 0,00 & 0,01 & - & 0,01 & 0,00 & 0,00 & 1,00 \\
Total & 1,66 & 2,23 & 0,02 & 0,00 & 0,05 & 0,00 & 0,05 & 0,00 & 0,02 & 4,04 \\
\hline
\end{tabular}

Fonte: Elaborado pelos autores com dados da empresa (2010) 
Tabela 10 - Quantidade produzida utilizada para apuração dos custos

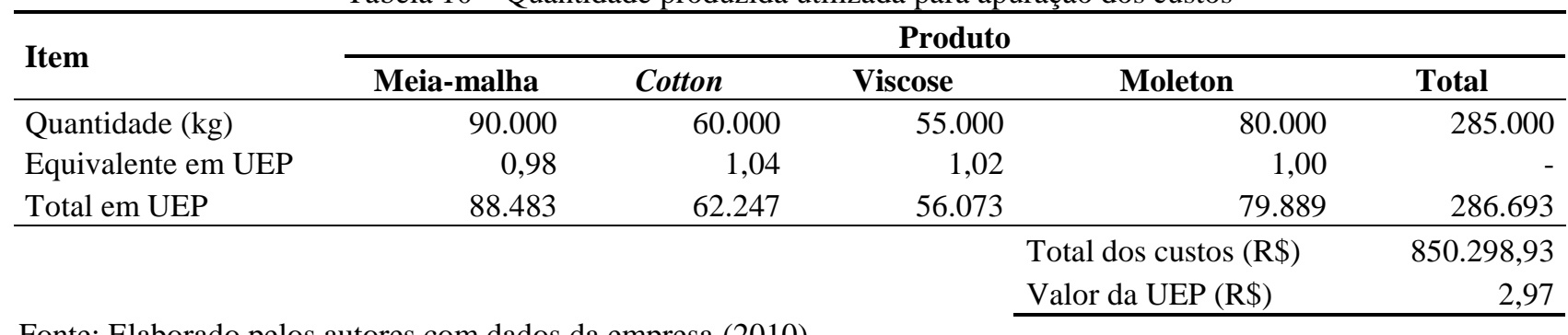

Fonte: Elaborado pelos autores com dados da empresa (2010)

O custo de uma UEP encontrado foi de 2,97. Multiplicando-se este valor pelo custo equivalente em UEP de cada produto, encontra-se o custo de transformação unitário de cada um (Tabela 11). Percebe-se que cada produto obteve um valor unitário diferente. Para se fabricar o mais caro (cotton), pode-se dizer que a fábrica realiza um maior esforço em relação aos demais produtos.

Tabela 11 - Custo de transformação de cada produto

\begin{tabular}{lrrrrr}
\hline \multirow{2}{*}{ Item } & \multicolumn{3}{c}{ Produto } & \multicolumn{2}{c}{ Motal } \\
\cline { 2 - 6 } & Meia-malha & Cotton & \multicolumn{1}{c}{ Viscose } & Moleton & \multicolumn{1}{c}{ Total } \\
\hline Custo de transformação unitário (R\$) & 2,92 & 3,08 & 3,02 & 2,96 & 2,98 \\
Quantidade produzida (kg) & 90.000 & 60.000 & 55.000 & 80.000 & 285.000 \\
Custo de transformação total $(\mathrm{R} \$)$ & $262.431,40$ & $184.618,52$ & $166.307,42$ & $236.941,59$ & $850.298,93$ \\
\hline
\end{tabular}

Fonte: Elaborado pelos autores com dados da empresa (2010)

Atualmente, a empresa apura os custos por meio de planilhas eletrônicas e utiliza como método o custeio por absorção tradicional, tendo como direcionadores de rateio para os custos indiretos as horas/máquinas (Tabela 12).

Aplicando o método tradicional com os mesmos dados do período em análise, a empresa atinge os custos unitários de transformação dos produtos (Tabela 13). Observa-se que os produtos cotton e viscose possuem custos parecidos e são bem maiores que os da meia-malha e do moleton

Tabela 12 - Custo totais de transformação dos produtos pelo método de absorção tradicional (R\$)

\begin{tabular}{lrrrrrrrrrr}
\hline \multirow{2}{*}{ Produto } & \multicolumn{10}{c}{ Posto operativo } \\
\cline { 2 - 11 } & P.01 & P.02 & P.03 & P.04 & P.05 & P.06 & P.07 & P.08 & P.09 & Total \\
\hline Meia-malha & 69.428 & 43.571 & 38.161 & - & -34.136 & 22.894 & - & - & 6.306 & 214.497 \\
Cotton & 71.362 & 46.431 & 44.007 & 1.043 & - & - & 42.986 & - & 10.949 & 216.777 \\
Viscose & 68.632 & 45.952 & - & 1.043 & 35.203 & - & 38.507 & - & 10.458 & 199.795 \\
Moleton & 65.811 & 45.613 & 24.449 & 5.563 & 29.869 & - & 24.760 & 13.074 & 10.090 & 219.230 \\
Total & 275.232 & 181.567 & 106.617 & 7.650 & 99.208 & 22.894 & 106.252 & 13.074 & 37.804 & 850.299 \\
\hline
\end{tabular}

Fonte: Elaborado pelos autores com dados da empresa (2010)

Tabela 13 - Custos unitários de transformação dos produtos pelo método de absorção tradicional

\begin{tabular}{lrrrrr}
\hline \multirow{2}{*}{ Item } & \multicolumn{5}{c}{ Produto } \\
\cline { 2 - 6 } & Meia-malha & \multicolumn{1}{c}{ Cotton } & \multicolumn{1}{c}{ Viscose } & \multicolumn{1}{c}{ Moleton } & Total \\
\hline Custo total de transformação $(\mathrm{R} \$)$ & 214.497 & 216.777 & 199.795 & 219.230 & 850.299 \\
Quantidade produzida $(\mathrm{kg})$ & 90.000 & 60.000 & 55.000 & 80.000 & 285.000 \\
Custo de transformação unitário $(\mathrm{R} \$ / \mathrm{kg})$ & 2,38 & 3,61 & 3,63 & 2,74 & 2,98 \\
\hline
\end{tabular}

Fonte: Elaborado pelos autores com dados da empresa (2010)

Comparado ao custeio por absorção, os custos dos produtos cotton e viscose no UEP foram 
$15 \%$ e $17 \%$ abaixo, respectivamente, enquanto que a meia-malha teve um aumento de $22 \%$ e o moleton de $8 \%$. Por ter sido o produto que foi produzido em maior quantidade, a meia-malha obteve o menor custo unitário. Observa-se que o produto mais caro foi o cotton e o mais barato foi a meia-malha, nos dois métodos (Tabela 14).

Tabela 14 - Comparativo de custos unitários de transformação entre os métodos de custeio (R $\$ / \mathrm{kg}$ )

\begin{tabular}{lcccc}
\hline \multirow{2}{*}{ Item } & \multicolumn{3}{c}{ Produto } \\
\cline { 2 - 5 } & Meia-malha & Cotton & Viscose & Moleton \\
\hline Custeio por Absorção (R\$) & 2,38 & 3,61 & 3,63 & 2,74 \\
Custeio UEP (R\$) & 2,92 & 3,08 & 3,02 & 2,96 \\
Variação (\%) & $22 \%$ & $-15 \%$ & $-17 \%$ & $8 \%$ \\
\hline Fonyyyyyyyyyyy
\end{tabular}

Fonte: Elaborado pelos autores com dados da empresa (2010)

No custeio por absorção, os produtos que foram produzidos em menores quantidades (cotton e viscose) sofreram um maior impacto no custo, obtendo-se unitários mais elevados. Enquanto que no método UEP ocorre uma distribuição de custos mais equilibrada, independente da quantidade produzida, com valores maiores de custos para os produtos que realizam mais esforços nas máquinas, não somente os que levam mais tempo nas máquinas.

Conforme verificado neste experimento prático, a evidenciação de informação que pode melhor auxiliar o gestor na decisão sobre o portfólio dos produtos da empresa caracteriza uma vantagem econômica para o UEP em relação ao método de custeio por absorção tradicional utilizado.

\section{Considerações Finais}

Nas seções precedentes, foi possível constatar que o método de custeio UEP é conhecido, porém não aplicado no parque têxtil do estado do Ceará. Muitas empresas possuem seu sistema de custos integrado configurado ou seu pessoal já foi treinado de acordo com o método de custeio que utilizam, mesmo com a preponderância ainda de planilhas para apuração de custos em vez de sistemas integrados. Portanto, a mudança para outro método seria algo que demandaria tempo e dinheiro, sendo necessária uma análise de custo-benefício, com o risco inerente dos pioneiros. Mesmo a já elevada competição no setor ainda não foi suficiente, como esperava Aguirre (1998), para provocar a adoção do UEP e de outros métodos de custeio mais modernos.

Além disso, percebeu-se que as IES do estado do Ceará não dão destaque ao método, preferindo transmitir os mais populares na literatura, como os tradicionais e o ABC. Diversas instituições não abordam o método ou apenas o abordam superficialmente, o que contribui para que os profissionais da área de custos não demonstrem maior interesse pelo método UEP. Para uma maior difusão do método, seriam necessários mais cursos, palestras e congressos mostrando as vantagens e a aplicabilidade do UEP em empresas multiprodutoras, com exemplos práticos de 
empresas de outras regiões do país ou do exterior.

Por não existirem empresas de consultoria ou mesmo outras empresas industriais no estado do Ceará que propaguem o método, a observação prática torna-se difícil. Empresas situadas no sul e sudeste do país que usam o UEP poderiam contribuir para a divulgação e o crescimento do método caso instalassem unidades industriais no Ceará.

Pelo estudo de caso, verificou-se que o método de custeio UEP não apresenta barreiras técnico-conceituais para uso em organizações industriais do ramo têxtil. Basta conhecer a estrutura fabril, especificar os postos operativos de forma clara para a obtenção de informações extracontábeis, e construir um sistema de informações que permita que os custos sejam atribuídos aos postos operativos adequadamente. E a empresa ainda teria a facilidade de estar de acordo com o fisco bem como com os princípios fundamentais de contabilidade, podendo inclusive elaborar demonstrativos para os usuários externos utilizando tal método. Principalmente, o estudo de caso ratifica a existência de vantagem econômica para as empresas industriais têxteis que substituam o método de custeio tradicional baseado em volume pelo UEP, por permitir uma apuração de custo de produtos mais precisa e decisões mais eficazes sobre preços e portfólio de produtos, em um ambiente de negócios altamente competitivo.

Portanto, dentre os fatores que influenciam a difusão das inovações, apontados por Diamond (2005), a dificuldade de se observar as vantagens e a necessidade de investimento em capital físico e intelectual surgem como as principais barreiras ao uso do UEP nas empresas têxteis cearenses.

\section{Abstract}

The Production Effort Unit (PEU) costing method is based on the notion of production effort, this is, effort of factors directly or indirectly applied in the manufacturing of the product, treating multiproduct entities as single-product ones, in order to determine the unit cost of their products. The purpose this article is to identify the determinants of the diffusion of the PEU costing method in the Ceará State textile industry. It encompasses a qualitative research using a semi-structured questionnaire applied in textile firms located in Ceará, followed by a documental research with Ceará State higher education institutions, both complemented by a case study of a local company of textile sector. The analysis has revealed that there are economic benefits by adopting the PEU over the traditional absorption costing method, more frequently used. However, the investment legacy in physical and intellectual capital to use other costing methods in the Ceará textile park, and the difficulty to observe the benefits of PEU, both in academia and in other companies, have been revealed as the main causes of the PEU non-adoption in the Ceará textile park to this moment.

Key-words: production effort unit; costing methods; textile industry.

\section{Referências}

ABIT. ASSOCIAÇÃO BRASILEIRA DA INDÚSTRIA TÊXTIL E DE CONFECÇÕES. Perfil geral do setor têxtil e de confecções. São Paulo: ABIT, $\mathbf{1}^{\mathbf{0}}$ de março de 2010. Disponível em: <http://www.abit.org.br/site/navegacao.asp?id_menu=6\&id_sub=19\&idioma=PT>. Acesso em: 07 de jul. 2010.

AGUIRRE, J. F. Mudança organizacional e a difusão de métodos de custeio no Brasil. Dissertação de mestrado. 
Universidade Estadual de Campinas. Campinas, SP [s.n.], 1998.

ALLORA, F.; ALLORA, V. UP: Unidade de medida da produção para custos e controles gerenciais das fabricações. $1^{\mathrm{a}}$ ed. São Paulo: Pioneira, 1995.

ATKINSON, A. A. et al. Contabilidade gerencial. 2a ed. São Paulo: Atlas, 2008.

BLOCHER, E. I. et al. Gestão estratégica de custos. São Paulo: McGraw Hill, 2007.

BORNIA, A. C. Análise gerencial de custos. Porto Alegre: Bookman, 2002.

BRIMSON, J. A. Contabilidades por atividades. São Paulo: Atlas, 1996.

BRUNI, A. L.; FAMÁ, R. Gestão de custos e formação de preços: com aplicações na calculadora HP 12C e Excel. $3^{\mathrm{a}}$ ed. São Paulo: Atlas, 2004.

DIAMOND, J. M. Armas, germes e aço: os destinos das sociedades humanas. $7^{\text {a }}$ ed. Rio de Janeiro: Record, 2005.

FERREIRA, J. A. S. Contabilidade de custos. São Paulo: Pearson Prentice Hall, 2007.

FRAGA, M. S. et al. Unidade de esforço de produção e utilização do plano-seqüiência. $6^{\circ}$ Congresso USP Controladoria e Contabilidade, São Paulo, SP, Brasil, $2006 . \quad$ Disponível em: <http://www.congressousp.fipecafi.org/artigos62006/175.pdf>. Acesso em: 15 de fevereiro de 2010.

GIL, A. C. Como elaborar projetos de pesquisa. 4. ed. São Paulo: Atlas, 2002.

INEP. Instituições de Educação Superior e Cursos Cadastrados. 2010. Disponível em: 〈http://emec.mec.gov.br/> . Acesso em: 15 de abril de 2010.

IBGE. Cadastro central de empresas. 2008. Disponível em: <http://www.sidra.ibge.gov.br/bda/tabela/protabl.asp?c=987\&z=t\&o=12\&i=P>. Acesso em: 07 de maio de 2010.

KAPLAN, R. S.; ANDERSON, S. R. 2004. Time-driven activity-based costing. Harvard Business Review, v.82, n.11, November, p.131:8.

LEONE, G. Curso básico de contabilidade de custos. São Paulo: Atlas, 2000.

MARTINS, E. Contabilidade de custos. 9ª ed. São Paulo: Atlas, 2008.

NAKAGAWA, M. ABC: custeio baseado em atividades. São Paulo: Atlas, 1994.

O POVO. Delmiro Economia e Negócios: as maiores e melhores empresas do Ceará. Fortaleza: O Povo, Novembro/2009.

PADOVEZE, C. L. Curso básico gerencial de custos. $2^{\text {a }}$ ed. rev. e ampl. São Paulo: Pioneira, 2006.

SAKAMOTO, F. T. C. A gestão da produção e gestão de custo através da UP - Unidade de Produção: fase de pósimplantação da UP na Seara Alimentos S.A. IN: ENEGEP, 23, 2003. Anais... Disponível em: <http://www.abepro.org.br/biblioteca/ENEGEP2003_TR0111_0059.pdf>. Acesso em: 10 de abr. 2010.

SANTOS, A. R.. Metodologia científica: a construção do conhecimento. 7. ed. Revisada conforme NBR 14724:2005. Rio de Janeiro: Lamparina, 2007.

WALTER, F. et al. Análise comparativa dos métodos de custeio "Unidades de Esforço de Produção" e “Äquivalenzziffern” (Cifras de Equivalência). IX Congresso Internacional de Custos, Florianópolis, SC, Brasil, 2005. Disponível em: <http://www.ucla.edu.ve/DAC/departamentos/coordinaciones/costoI/Congreso\%20Internacional\%20de\%20Costos/VO L_200511232139\%20(D)/artigos/custos_542.pdf>. Acesso em: 10 de abr. 2010.

WERNKE, R. Gestão custos: uma abordagem prática. 2a . ed. São Paulo: Atlas, 2004.

WERNKE, R. Análise de custos e preços de venda: ênfase em aplicações e casos nacionais. São Paulo: Saraiva, 2005.

\section{Dados dos autores:}


Nome completo: Leonardo Almeida de Sousa

Filiação institucional: Universidade Federal do Ceará - UFC

Departamento: Contabilidade

Função ou cargo ocupado: Discente do Curso de Especialização em Controladoria

Endereço completo para correspondência (bairro, cidade, estado, país e CEP): Rua Uirapuru, 513 Maraponga, Fortaleza, Ceará, Brasil, CEP 60.711-790

Telefones para contato: (85) 8815-1437

e-mail: leonardo.almsousa@gmail.com

Nome completo: Hugo Santana de Figueirêdo Junior

Filiação institucional: Universidade Federal do Ceará - UFC

Departamento: Contabilidade

Função ou cargo ocupado: Professor Assistente

Endereço completo para correspondência (bairro, cidade, estado, país e CEP): Departamento de Contabilidade, Av. da Universidade, 2.431, Benfica, Fortaleza, Ceará, Brasil, CEP 60.020-180

Telefones para contato: (85) 3366-7802, 3366-7801

e-mail: hugo.figueiredo@ufc.br

Enviado em: 02/06/2011

Aprovado em: 01/03/2012 